\title{
A Study to Assess the Knowledge Regarding Occupational Hazards and Utilization of Safety Measures among Construction Labourers at Selected Construction Sites of Jodhpur
}

\author{
Mukesh Soni ${ }^{1}$, Parvej Khan ${ }^{2}$ \\ Public Health Nursing Officer, All India Institute of Medical Sciences, Jodhpur ${ }^{1}$ \\ Nursing Lecturer, Department-Medical Surgical Nursing ${ }^{2}$
}

\section{Abstract}

\section{$>$ Introduction}

Work plays an important role in people's lives as most workers spend at least 8 hours a day in the workplace whether it be in a building, office or factory. Occupational health is also a health concern regarding work and work. Occupational health not only protects health but also promotes health, emergency care, a wide range of preventative, therapeutic, rehabilitation services, an all-encompassing concept that can work to promote the health and wellbeing of employees. Construction work is considered a physically demanding task, usually under difficult conditions including hot, cold or wet weather. Construction workers closest to immigrants and members of other low-income groups are dealing with illness and injury resulting from work.

\section{$>$ Material and Methods}

Quantitative descriptive survey study approach and non experimental research design was used.Total 50 construction labourers working in construction site Jodhpur were selected by purposive sampling technique.Data collection by structured knowledge questionnaire and analysed by using descriptive and inferential statistics.

\section{$>$ Result}

Majority $(60 \%)$ of the sample had average knowledge, and rest of $40 \%$ samples had good knowledge regarding occupational hazards and utilization of safety measures.The overall knowledge score with mean $\pm \mathrm{SD}$ is $\mathbf{1 9 . 8 8} \pm \mathbf{2 . 0 0 7}$ and mean percent knowledge of $66.27 \%$

\section{$>$ Conclusion}

It was evident that there was a statistically significant relationship between the knowledge of construction workers on the different materials selected. Gender variables, Monthly Income and Work Experience found significant relationships at the $\mathbf{0 . 0 5}$ level and, religion and educational status were not significant at the 0.05 level. Thus the old saying that there would be a significant relationship between the knowledge of construction workers in relation to occupational hazards and the use of safety and diversity measures is welcome.

Keyword:- $\quad$ Assess, Knowledge, Construction labourers, Occupational hazards, Safety measures.

\section{INTRODUCTION}

Occupational health nurse is concerned with the nurse's role in obtaining comprehensive health care at work and is instrumental in improving health care, protecting the health of disabled employees. Nurses on the job can play a major role in the promotion, prevention, prevention and management of diseases and disabilities. His colleagues make up the biggest and most important team in the world. The global workforce is almost 2600 million and $75 \%$ of these people work in developing countries. The total workforce in India is estimated at 317 million and the official sector spends only 26.8 Million (8.5\%) on the unauthorized sector, reaching 290,2 million (91.5\%). The Indian sector remains hard-working and often uses inexpensive and risky technology because of the financial crisis and is especially true in the less formal sector. The Construction Industry is one of the fastest-growing industries in the world, including India. It's a working class. It employs a large portion of the population. Construction contracts are often members of the informal economy and consequently have no basic assets. Apart from this, most of the construction projects or sites where the workers are working are not structured naturally. Thus, these areas are often not governed by laws designed for the health and well-being of workers.

Construction is one of the key industries that employs a large number of its employees. There are many different functions involved. Due to the advent of industrialization and recent developments, this sector plays an important role in the construction of buildings, roads, bridges and so on. Workers in this sector are victims of job disruption and stress. In India, they are members of organized and organized sectors. However, data on mental health and mental health pressure are limited in our country. It is true that a large number of workers come from informal sectors - long hours of work - the work environment is not good working conditions are not expected in many cases and involve risks. Their pay is also inadequate, making it 
difficult for them to run their families. They tend to work when there are excessive noise levels and with tools and equipment that produce dangerous movements to perform repetitive tasks, strong motives and negative thinking, often use toxins and mutations and have to deal with constantly changing work situations. with many freelance staff working in different jobs at the same time, while managing themselves during most of the day. Workers in the construction industry are especially at risk because the work is short-lived, employer-employee relations are weak and short-lived, work life and arms are due to lack of safety, health and social structures. uncertain working hours.

\section{MATERIAL AND METHOD}

A quantitative descriptive design was adopted in the study. The population consisted of shriram hospitals at
Jodhpur. A sample size of 50 construction labourers was selected using purposive sampling.A structure questionnaire was adopted by the investigator for data collection. The tool structured knowledge questionnaire is validated by experts. Reliability of the tool was done using Karl Pearson (Co-relation, co-efficient) formula.Statistical procedure enables the researcher to organize, analyse, interpret, evaluate and communicate numerical information meaningfully. Results were computed by using SPSS Ver.23 , based on the objectives of the study.

\section{RESULT}

Table No. 1 shows that majority $(60 \%)$ of the sample had average knowledge, and rest of $40 \%$ samples had good knowledge regarding occupational hazards and utilization of safety measures.

\begin{tabular}{|c|c|c|}
\hline Level of Awareness & Frequency & Percentage \\
\hline Poor & 0 & $0 \%$ \\
\hline Average & 30 & $60 \%$ \\
\hline Good & 20 & $40 \%$ \\
\hline
\end{tabular}

Table 1:- Frequency and percentage distribution of the levels of knowledge regarding occupational hazards and utilization of safety measures. $(\mathrm{N}=50)$

Table No. 2 indicates that the knowledge level of construction workers based on various occupational hazards and safety measures was highest (70.67\%) with regard to 'personal practices' with mean \pm SD $2.12 \pm 0.718$, followed by $70 \%$ with respect to general awareness of emergencies and action taken with an emergency time 'with $\pm \mathrm{SD}$ of $2.8 \pm 0.404,65.71 \%$ with regard to' medical examination, training and use of safety measures' with mean \pm SD of $9.20 \pm 0.990,65.60 \%$ with regard to
'Occupational Hazards and their type' with mean \pm SD of $3.28 \pm 0.536$ and lowest $(62 \%)$ in relation to 'Health problems occurring on site and causes' with a mean \pm SD of $2.48 \pm 0.505$. The total knowledge score with \pm SD is 19.88 \pm 2.007 and mean information is $66.27 \%$. Based on our findings we may conclude that the knowledge of construction workers should be a benchmark for all aspects related to occupational hazards and the use of safety measures.

\begin{tabular}{|l|l|l|l|l|l|}
\hline S.No. & Awareness Aspects & Maximum & Mean & \pm S.D. & Mean \% \\
\hline 1 & Occupational hazards and their type & 5 & 3.28 & 0.536 & $65.60 \%$ \\
\hline 2 & Health problems occurs at construction site and causes & 4 & 2.48 & 0.505 & $62.00 \%$ \\
\hline 3 & $\begin{array}{l}\text { General awareness about emergency and action taken during } \\
\text { emergency }\end{array}$ & 4 & 2.80 & 0.404 & $70.00 \%$ \\
\hline 4 & $\begin{array}{l}\text { Medical check-up, Training and utilization of safety } \\
\text { Measures }\end{array}$ & 14 & 9.20 & 0.990 & $65.71 \%$ \\
\hline 5 & Personal habits & 3 & 2.12 & 0.718 & $70.67 \%$ \\
\hline \multicolumn{1}{|c|}{ Overall } & $\mathbf{3 0}$ & $\mathbf{1 9 . 8 8}$ & $\mathbf{2 . 0 0 7}$ & $\mathbf{6 6 . 2 7 \%}$ \\
\hline
\end{tabular}

Table 2:- Aspects wise mean knowledge score regarding occupational hazards and utilization of safety measures. ( $\mathrm{N}=50)$

\section{CONCLUSION}

Study show that Major $(60 \%)$ of the sample had medium information, while $40 \%$ of the samples had good information about occupational hazards and the use of safety measures. There was a relationship between the knowledge of construction workers and the variety of areas such as gender, Monthly Income and practical experience, which is why, Hypothesis ( $\mathrm{H} 1)$ has a relationship between the knowledge and flexibility of diversity of construction workers' gender identity, Monthly Income and Work Experience. There was no significant relationship between knowledge building $\square$ abourers and ownership variables such as gender, Monthly Income and Working Experience which is why Hypothesis (H1) has a significant relationship between the knowledge and flexibility of selected construction workforce statistics and diversity of gender such as gender, Monthly income and work experience. 


\section{REFERENCS}

[1]. Sebastian K., Occupational Health Risk and Problems in India. Health Action 2002 Feb; 15. Page no 3-8.

[2]. TNAI. Public Health Nurse Handbook. 3rd edition, TNAI Publication; 1998. Pages 51-53.

[3]. Gullani K K., Public Health Nurse, Principles and Practices, First Edition; Kumar Publishing House: 2005.page No.254-255.

[4]. Brindha V. Preventing Occupational Health Risks among stoneworkers. Nightingale Nursing Times 2005 Dec; 1, Page No 17-19.

[5]. Knut Ringen, a construction workers' guide to poisoning the workplace. Berkeley: California Publication Foundation, 1993. page No.101-105.

[6]. Department of Health and Human Services of England. Health and Safety, Maryland; National Institute of Health: 1993.

[7]. International labor conference, sixty-two session. Amendments to the list of chronic diseases included in the Workplace Injury Benefits Summit. No. 121; 1964.

[8]. Wong TW. Workplace injuries among construction workers in Hong Kong, occupational medicine 1994 44 (1); 247-252

[9]. Benavides FG, Associations between Temporary Employment and Workplace Injury: Occup environ Med 2006 Jan; 63 (6): 416-21.

[10]. Brindha V. Preventing occupational health hazards among stoneworkers. Nightingale Nursing Times 2005 Dec; 1 (9): 17-9.

[11]. Dong, Effects of safety and health training on workrelated injuries among construction workers. Occupational and Environmental Medical Journal 2004 Dec; 46 (12): 1222-8.

[12]. Sharma A, Thomas S, Dagli RJ, Solanki J, Arora G, Singh A. Oral health status of cement factory workers, Sirohi, Rajasthan, India. J Health Res Rev [serial online] 2014 (cited2016-july-24) 1: 15-9.

[13]. Guddi Tiwary and P. K. Gangopadhyay, Department of Epidemiology, Institutional Health Center (E), Indian Medical Research Council, Indian J Occup Environ Med. 2011 Jan-Apr.

[14]. Kuruvila Skin disease pattern among migrant construction workers in Madabad. Indian J Dermotal Veneral Leprol 2006; A 72 (2): 129-32.

[15]. Zwerling, Craig, Damage among construction workers in rural areas: a review by the Emergency Department. Occupational and Environmental Medical Journal 1996 July; 38 (7): 698-704. 